\title{
Peranan Kedutaan Besar Republik Indonesia dalam Menanggulangi Persoalan Tenaga Kerja Indonesia di Malaysia
}

\begin{abstract}
Abdul Hariss ${ }^{1}$
Abstrak

Pemerintah Republik Indonesia yang berkewajiban melindungi para warga negarannya dimanapun berada, dengan menugaskan Kedutaan Besar untuk mengatasi permasalahan yang dihadapi. Salah satu yang yang perlu dilakukan adalah perlindungan hukum bagi Tenaga kerja Indonesia khususnya yang berada di Malaysia, Peran Kedutaan Besar Indonesia di Malaysia menugaskan diantaranya Konsuler Atase Imigrasi untuk menangani urusan surat menyurat (administrasi) tenaga kerja Indonesia di Malaysia baik sebagai pelancong (turis) maupun sebagai tenaga kerja Indonesia. Disaat penghidupan pekerjaan di dalam negeri semakin sempit maka menjadi salah satu pilihan yang menjanjikan dalam menompang nafkah hidup keluar untuk mencari penghidupan ke luar negeri salah satunya Malaysia yang menjadi salah satu tujuan utama bagi masyarakat Indonesia dalam mencari penghidupan yang layak. Penghidupan yang menjanjikan untuk bekerja diluar negeri menimbulkan banyak manfaat kebaikan maupun permasalahan yang timbul baik penyaluran secara Legal maupun secara Ilegal, bagi para Tenaga kerja Selain dalam menafkahi keluarga bagi tenaga kerja Indonesia yang bekerja diluar negeri akan menambah kesejahteraan bagi keluarganya didaerah selain itu juga dapat menambah defisa bagi negara sehingga para pekerja yang bekerja diluar negeri menjadi pahlawan defisa bagi negara, maka selayaknya para tenaga kerja diberi perlindungan hukum yang baik. Karena negara harus hadir melindungi segenap warga negeranya dimanapun berada.
\end{abstract}

Kata Kunci: Perlindungan hukum, Tenaga kerja Indonesia

\begin{abstract}
The Government of the Republic of Indonesia that is obliged to protect its citizens wherever they are located, with negarannya commissioned the Embassy to address problems encountered. The one that needs to be done is legal protection for the workforce of Indonesia in particular who are in Malaysia, the role of the Embassy of Indonesia in Malaysia of which commissioned the Consular Affairs to handle Immigration Attaches correspondence (Indonesia's labor Administration) in Malaysia as both travelers (tourists) as well as Indonesia's labor. When livelihoods work in the country's increasingly narrow then becomes one of a promising option in menompang a living life out to seek livelihoods abroad, one of which was Malaysia which became one of the main goals for the community Indonesia in search of a decent livelihood. Livelihood that promises to work outside the country raises many of the benefits of kindness as well as problems that arise either channelling legally or illegally, for the workforce in addition in the menafkahi family for labor Indonesia working outside the country will add to his family's prosperity for the regions in addition can also add defisa to the country so that workers who work outside of the country became the hero of the defisa for the State, then the labor should be given good legal protection. Because
\end{abstract}

${ }^{1}$ Dosen Fakultas Hukum Universitas Batanghari 
the State must be present to protect all the citizens of the respective countries anywhere.

Keywords: legal protection of labour, Indonesia

\section{PENDAHULUAN}

Semakin tingginya usia produktif bangsa Indonesia tetapi tidak diimbangi dengan luasnya lapangan kerja yang tersedia dan/atau tidak sesuainya pendapatan dengan kebutuhan hidup di negara ini, maka banyak warga negara Indonesia mengadu nasibnya mencari pekerjaan di negara tetangga, salah satunya adalah negara Malaysia.

Negara Malaysia dijadikan sasaran untuk mencari pekerjaan adalah karena lapangan pekerjaan yang tersedia sangat luas, penghasilan yang didapat cukup tinggi dibandingkan di negara sendiri dan hasil yang didapat memungkinkan hidup layak di negara Indonesia.

Setiap orang diseluruh dunia mempunyai hak bergerak kemanapun dia inginkan, tetapi pergerakan yang dilakukan tidak selamanya dapat ditolerir oleh setiap negara, sehingga ada istilah pencegahan dan penangkalan terhadap orang yang akan masuk ke suatu negara.

Kebebasan bergerak itu dibatasi dengan keamanan nasional, ketertiban umum, kesehatan dan moral masyarakat dan kepentingan masyarakat.Setiap pembatasan yang dapat dilakukan oleh setiap Negara harus berdasarkan alasan yang jelas secara hukum dan rasional.

Pembatasan hak atas kebebasan bergerak ini dapat dilakukan oleh setiap Negara dengan cara pencegahan dan penangkalan, pencegahan dan penangkalan adalah untuk menghentikan seseorang untuk masuk atau keluar wilayah Negara yang bersangkutan atas dasar alasan-alasan yang secara rasional untuk keamanan nasional, ketertiban umum, kesehatan dan moral masyarakat dan kepentingan masyarakat. Definisi Pencegahan menurut Undang-Undang Nomor 9 tahun 1992 tentang keimigrasian adalah Larangan yang bersifat sementara terhadap orangorang tertentu untuk keluar dari wilayah Indonesia berdasarkan alasan tertentu. Sedangkan penangkalan adalah larangan yang bersifat sementara terhadap orangorang tertentu untuk masuk kewilayah Indonesia berdasarkan alasan tertentu.Penggunaan pencegahan dan penangkalan ini tidak boleh digunakan sewenang-wenang oleh suatu Negara, Negara harus tetap menjamin hak atas kebebasan bergerak setiap individu namun juga harus menjalankan kepentingan nasionalnya. Penggunaan pencegahan dan penangkalan ini harus benar-benar dengan alasan yang kuat dan rasionil dan berlandaskan hukum untuk alasan keamanan nasional, ketertiban umum, kesehatan dan moral masyarakat dan kepentingan masyarakat yang sesuai dengan kovenan internasional dalam hak sipil dan politik. ${ }^{2}$

Negara Malaysia sangat senang menerima tenaga kerja asing dari luar negeri dengan perhitungan upah yang diberikan lebih rendah dari pada upah bagi tenaga kerjanya sendiri, namun tidaklah mampu menerima semua tenaga kerja asing yang masuk, sehingga ditentukan kuota dalam penerimaan tenaga kerja asing yang masuk, tak terkecuali tenaga kerja Indonesia.

${ }^{2}$ Rega Felix, woordpress.com/2011/01/15/penerapan-dan-penggunaan-pencegahan-danpenangkalan-keimigrasian-dalam-perspektif-hak-atas-kebebasan-bergerak. 
Bagi para tenaga kerja Indonesia yang benar-benar sangat membutuhkan pekerjaan, tetap banyak mengalir ke negara Malaysia, baik secara legal diurus oleh pemerintah maupun yang ilegal melalui biro-biro perjalanan yang tak bertanggung jawab.Untuk tahun 2017 saja terdata bahwa tenaga kerja resmi Indonesia yang berada di Malaysia sebanyak 4 juta orang dan yang ilegal sebanyak 1,5 juta orang.

Banyaknya tenaga kerja Indonesia yang masuk ke negara Malaysia, terutama tenaga kerja Indonesia illegal menimbulkan banyaknya permasalahan bagi pemerintah Malaysia maupun pemerintah Indonesia.Bagi pemerintah Malaysia dalam menghadapi permasalahan itu adalah mengembalikan tenaga kerja Indonesia ke negaranya dengan kegiatan deportasi dan tak jarang terjadi kekerasan terhadap tenaga kerja Indonesia yang tetap membangkang masuk secara ilegal.

Permasalahan yang terjadi bukan itu saja, saking banyaknya tenaga kerja Indonesia di Malaysia, semakin banyak tindak pidana yang terjadi, baik terhadap tenaga kerja Indonesia maupun bagi warga negara Malaysia. Dan tak segan-segan pemerintah Malaysia menjatuhkan pidana bagi tenaga kerja Indonesia, tak terkecuali pidana mati, yang hingga sekarang telah dituntut pidana mati sebanyak 93 (sembilan puluh tiga) orang sedangkan sebelumnya telah dijatuhi hukuman mati kepada 66 (enam puluh enam) orang warga negara Indonesia.

Dengan keadaan tersebut di atas, pemerintah Republik Indonesia yang berkewajiban melindungi para warga negarannya dimanapun berada, menugaskan Kedutaan Besar untuk mengatasi permasalahan yang dihadapi. Kedutaan Besar Indonesia di Malaysia menugaskan diantaranya Konsuler Atase Imigrasi untuk menangani urusan surat menyurat (administrasi) tenaga kerja Indonesia di Malaysia baik sebagai pelancong (turis) maupun sebagai tenaga kerja Indonesia.

Permasalahan administrasi atau surat masuk tenaga kerja Indonesia ke Malaysia berupa Paspor, Visa maupun permit sangatlah komplit, baik dari terus terjadinya penyelundupan tenaga kerja Indonesia maupun belum lengkapnya sarana prasarana keadministrasian Kedutaan Besar Indonesia umumnya dan atase imigrasi khususnya di Malaysia.

Permasalahan tersebut di atas umumnya diketahui pada saat tenaga kerja Indonesia akan meminta perpanjangan masa berlakunya paspor, visa ataupun permit kepada Kedutaan Besar Indonesia di Malaysia.

\section{Rumusan Permasalahan}

1. Apasaja bentuk permasalahan administrasi tenaga kerja Indonesia di Malaysia?

2. Bagaimana peran kedutaan besar Indonesia di Malaysia dalam menyelesaikan permasalahan administrasi tenaga kerja Indonesia di negara Malaysia?

3. Apasaja kendala-kendala yang dihadapi dalam menyelesaikan permasalahan administrasi tenaga kerja Indonesia dan bagaimana upaya penanggulangan yang ditempuh?

\section{PEMBAHASAN}

\section{Bentuk Permasalahan Administrasi Tenaga Kerja Indonesia di Malaysia}

Sebagaimana diketahui bahwa tenaga kerja Indonesia banyak yang masuk dan bekerja di wilayah negara Malaysia, namun banyak diantara mereka menimbulkan permasalahan, baik yang dilakukan oleh tenaga kerja Indonesia resmi maupun oleh tenaga kerja Indonesia tidak resmi (ilegal). 
Umumnya permasalahan yang dilakukan oleh tenaga kerja Indonesia yang masuk ke wilayah Malaysia adalah permasalahan administrasi yang berkaitan dengan surat masuk ke negara lain, baik pasport maupun visa. Adapun bentuk permasalahan administrasi tenaga kerja Indonesia masuk ke Negara Malaysia dikatakan oleh Mulkan Lekat selaku Atase Imigrasi Kedutaan Besar Indonesia di Malaysia adalah berupa :

\section{Peran administrasi swasta yang tidak benar}

Pengurusan pengiriman tenaga kerja Indonesia ke Malaysia tidaklah seluruhnya dikelola oleh Pemerintah, melainkan ada pula dikelola oleh pihak swasta yang diketahui dan disetujui oleh pemerintah Indonesia. Pihak swasta berkewajiban menyiapkan semua persyaratan yang harus dipenuhi oleh tenaga kerja Indonesia yang akan masuk ke wilayah Malaysia terutama pasport tenaga kerja Indonesia dan selanjutnya mengajukan ke kantor Imigrasi Malaysia, guna mendapatkan visa atau permit tenaga kerja Indonesia masuk ke wilayah negara Malaysia.

Setelah adanya visa ataupun permit dari pemerintahan Malaysia, barulah tenaga kerja diberangkatkan ke negara Malaysia. Tenaga Kerja Indonesia yang dberangkatkan ke Malaysia adalah orang yang berhak atas visa tersebut sebagaimana yang dimohonkan sebelumnya.

Tenaga kerja Indonesia yang bekerja di Malaysia ada yang lebih dari 5 (lima) tahun, sehingga masa berlaku paspor berakhir. Sebelum berakhirnya masa berlaku paspor, diharapkan tenaga kerja Indonesia di Malaysia memperpanjang masa berlaku paspornya.

Pada saat paspor diperpanjang, ditemui permasalahan oleh Atase Imigrasi Indonesia di Malaysia, yaitu paspor yang diajukan ternyata palsu akibat ulah dari perbuatan penyalur sawasta tenaga kerja Indonesia ke Malaysia.

Dikarenakan tidak telitinya kantor Imigrasi Malaysia atas paspor tenaga kerja Indonesia yang diajukan kepadanya, maka mereka mengeluarkan saja visa yang diinginkan oleh tenaga kerja Indonesia tersebut hingga berakhirnya masa berlaku paspor. Akibatnya paspor palsu tetapi visa resmi, yang jika diketahui oleh Imigrasi Malaysia, tenaga kerja Indonesia dapat ditangkap untuk melaksanakan ketentuan hukum yang berlaku di Malaysia atau dikembalikan ke negara Indonesia.

\section{Paspor Lewat Waktu}

Ternyata permasalahan paspor yang digunakan oleh tenaga kerja Indonesia di negara Malaysia tidak hanya paspor palsu, melainkan juga ada paspor yang telah berakhir masa waktunya.Tenaga Kerja Indonesia yang telah bekerja di negara Malaysia tidak mengurus perpanjangan paspornya padahal masa berlakunya telah berakhir.Agar mereka tidak dapat melanjutkan pekerjaan atau takut dikembalikan ke negara Indonesia, maka mereka melakukan perpanjangan paspor. Namun yang menjadi permasalahan, sebelum perpanjangan paspor dan mendapatkan kembali visa dari negara Malaysia, tenaga kerja Indonesia wajib meninggalkan negara Malaysia, apakah kembali ke negara Indonesia atau negara lain, yang penting dirinya tidak berada di negara Malaysia yang dianggap sebagai pendatang haram. 


\section{TKI bawa Keluarga}

Sebagaimana diketahui bahwa satu visa untuk satu orang tenaga kerja Indonesia, ternyata pada saat akan memperpanjang visa, ada tenaga kerja Indonesia yang masuk ke Malaysia membawa anggota keluarganya. Perbuatan tersebut sangat dilarang di negara Malaysia, sehingga Atase Imigrasi meminta agar anggota keluarga tenaga kerja Indonesia meninggalkan negara Malaysia jika ingin visa bekerja di negara Malaysia diperpanjang.

\section{TKI Tidak Punya Visa Masuk}

Selain permasalahan keadministrasian tersebut di atas ada lagi kasus yang sangat banyak jumlahnya, yaitu masuknya tenaga kerja Indonesia ke Malaysia tanpa mendapat visa terlebih dahulu dari pemerintahan Malaysia, sehingga mereka dikatakan pendatang haram oleh bangsa Malaysia. Merekapun masuk umumnya tidak juga melalui atase imigrasi Indonesia di Malaysia, melainkan sembunyi-sembunyi melalui perantara mereka yang tak bertanggung jawab.

\section{Peran Kedutaan Besar Indonesia di Malaysia dalam Menyelesaikan Permasalahan Administrasi Tenaga Kerja Indonesia di Negara Malaysia}

Permasalahan tenaga kerja Indonesia di Malaysia bukan hanya permasalahan administrasi keimigrasian, melainkan juga permasalahan tindak pidana yang lebih banyak merugikan tenaga kerja Indonesia, yang mana menurut Fajar Sulaeman T selaku Kepala Atase Hukum Kedutaan Besar Indonesia di Malaysia, hingga bulan Agustus 2017 warga negara Indonesia yang dipenjara di Malaysia sebanyak 4.973 (empat ribu sembilan ratus tujuh puluh tiga) orang, dengan rincian 4.061 (empat ribu enam puluh satu) orang laki-laki dan 912 (sembilan ratus dua belas) orang perempuan. Di samping 66 (enam puluh enam) orang telah dihukum mati, 93 (sembilan puluh tiga) orang warga negara Indonesia menunggu untuk dihukum mati pula di Malaysia.

Dengan banyaknya permasalahan yang timbul berkenaan dengan tenaga kerja Indonesia, sudah barang tentu tugas berat dipikul oleh Kedutaan Besar Indonesia di Malaysia, di samping harus tetap menjaga hubungan baik dengan negara Malaysia, juga harus melindungi warga negara Indonesia terutama tenaga kerja Indonesia di Malaysia. Agar dua tujuan tersebut tercapai, maka Kedutaan Besar Indonesia di Malaysia dituntut berperan penting dalam melakukan penanggulangan yang efektif dan efisien.

Peran Kedutaan Besar Indonesia di Malaysia dalam menyelesaikan permasalahan administrasi tenaga kerja Indonesia masuk ke negara Malaysia, diwujudkan dengan kegiatan-kegiatan :

\section{Menghimpun seluruh tenaga kerja Indonesia di Malaysia}

Sebagaimana diketahui bahwa tenaga kerja Indonesia yang masuk dan bekerja di Malaysia ada yang masuk secara legal dan adapula yang ilegal, maka melalui atase keimigrasian dan perangkat-perangkatnya, kedutaan besar Indonesia mengumpulkan data-data seluruh tenaga kerja Indonesia di Malaysia dan terus mencari para tenaga kerja yang tak terdaftar di atase keimigrasian karena masuk secara ilegal. Dalam hal penghimpunan seluruh tenaga kerja Indonesia ini, pihak Keduta Besaran Indonesia juga meminta bantuan dari kedutaan Besar Malaysia untuk menemukan dan menginformasikan tenaga kerja Indonesia yang ada di negara Malaysia. 
Mengembalikan tenaga kerja Indonesia yang tidak mempunyai kelengkapan administrasi

Setelah terhimpun dan diketahui adanya tenaga kerja Indonesia yang bermasalah dengan administrasi keimigrasian, Kedutaan Besar Indonesia mengembalikannya ke Indonesia untuk segera melengkapi administrasi keimigrasian jika masih ingin bekerja di negara Malaysia.

Pengembalian tenaga kerja Indonesia di Malaysia ke Indonesia dilakukan dalam waktu yang secepatnya walaupun ada yang memakan waktu beberapa minggu karena ada permasalahan teknis atau permasalahan tenaga kerja Indonesia dengan majikan dimana dia bekerja.

Kepulangan tenaga kerja Indonesia ke negara Indonesia diberikan SPLP agar tidak tertangkap oleh Kepolisian Imigrasi Malaysia. Pemberian SPLP ini khusus kepada tenaga kerja Indonesia yang tidak memiliki paspor atau permit dari pemerintah Malaysia.

Melarang Tenaga Kerja Indonesia masuk ke Malaysia tanpa administrasi keimigrasian

Melalui Pemerintahan di Indonesia, Kedutaan Besar Indonesia di Malaysia meminta kepada Pemerintah Indonesia untuk melarang para calon tenaga kerja Indonesia bekerja di Malaysia jika tidak cukup administrasi keimigrasian dan meminta Keimigrasian Indonesia lebih hati-hati dan teliti dalam pengiriman tenaga kerja Indonesia ke Malaysia.

Menindak Tegas Penyalur Tenaga Kerja Indonesia yang Tidak Bertanggung Jawab

Melalui Pemerintahan di Indonesia, Kedutaan Besar Indonesia meminta Pemerintah Indonesia untuk menindak tegas para penyalur tenaga kerja Indonesia yang tidak bertanggung jawab atau melakukan pelanggaran dalam penyaluran tenaga kerja Indonesia ke Malaysia, baik dilakukan terhadap penyalur resmi maupun penyalur tidak resmi. Tindakan tegas yang dimaksud adalah berupa sanksi pidana dan/atau pencabutan izin usaha penyaluran tenaga kerja Indonesia.

\section{Kendala-kendala yang Dihadapi dalam Menyelesaikan Permasalahan Administrasi Tenaga Kerja Indonesia dan Upaya Penanggulangan yang Ditempuh}

Terus terjadinya permasalahan keadministrasian tenaga kerja Indonesia yang masuk ke negara Malaysia, tidak terlepas dari kendala-kendala yang dihadapi Atase Imigrasi Indonesia di Malaysia, yang mana kendala yang dihadapi sebagaimana penjelasan Mulkan Lekan selaku Atase Imigrasi adalah :

\section{Dana Operasional Kurang}

Mayoritas setiap hari administrasi yang harus dikerjakan sebanyak 1000 (seribu) orang tenaga kerja Indonesia yang dikelola oleh 47 (empat puluh tujuh) orang pegawai, 3 (tiga) orang diantaranya adalah warga negara Malaysia. Untuk biaya operasional keadministrasian tenaga kerja Indonesia adalah sebesar Rp.7.000.000.000,- (tujuh milyar rupiah) per tahun, sedangkan yang ada sekarang untuk tahun 2017 hanya sebesar Rp.30.050.000,- (tiga puluh juta lima puluh ribu rupiah). 


\section{Kurangnya peralatan}

Daya dukung peralatan yang ada di Atase Imigrasi masih sangat kurang untuk memberikan pelayanan kepada tenaga kerja Indonesia, yaitu seperti peralatan SIMKIM, seharusnya 21 (dua puluh satu) set, tetapi yang ada baru 15 (lima belas) set.

\section{Kurangnya pegawai}

Pegawai keadministrasian di Atase Imigrasi masih kurang dari yang seharusnya, seperti :

1. Staf kurang 11 (sebelas) orang;

2. Pegawai loket baru 15 (lima belas) orang, seharusnya 21 (dua puluh satu) orang;

3. Pegawai loket Visa baru 6 (enam) orang seharusnya 9 (Sembilan) orang;

4. Staf Ajudicator baru 2 (dua) orang seharusnya 4 (empat) orang; dan

5. Pegawai pengambilan paspor baru 3 (tiga) orang seharusnya 5 (lima) orang.

Guna mengatasi kendala yang dihadapi tersebut, upaya penanggulangan yang ditempuh adalah :

1. Penambahan bantuan dana operasional

Terus dilakukan peningkatan dana operasional baik dari Kementerian Luar Negeri maupun Dipa Imigrasi.

\section{Penambahan Peralatan}

Terus dilakukan penambahan peralatan operasional yang dianggap masih kurang walaupun dilakukan secara bertahap.

3. Penambahan Karyawan

Meskipun penambahan karyawan bersangkut paut dengan dana, namun terus diusahakan penambahan karyawan walaupun secara bertahap sesuai dengan kesediaan dana yang ada.

\section{SIMPULAN}

1. Bentuk permasalahan administrasi tenaga kerja Indonesia masuk di negara Malaysia adalah berupa :

a. Peran administrasi swasta yang tidak benar

b. Paspor lewat waktu;

c. TKI bawa Keluarga; dan

d. TKI Tidak Punya Visa Masuk.

2. Peran Kedutaan Besar Indonesia di Malaysia dalam menyelesaikan permasalahan administrasi tenaga kerja Indonesia masuk ke negara Malaysia adalah dengan cara :

a. Menghimpun seluruh tenaga kerja Indonesia di Malaysia;

b. Mengembalikan tenaga kerja Indonesia yang tidak mempunyai kelengkapan administrasi;

c. Melarang Tenaga Kerja Indonesia masuk ke Malaysia tanpa administrasi keimigrasian; dan

d. Menindak Tegas Penyalur Tenaga Kerja Indonesia yang Tidak Bertanggung Jawab.

3. Kendala yang dihadapi dalam penyelesaian permassalahan administrasi tenaga kerja Indonesia di Malaysia adalah berupa :

a. Dana Operasional Kurang;

b. Kurangnya peralatan; dan 
c. Kurangnya pegawai.

Adapun upaya penanggulangan yang ditempuh oleh Kedutaan Besar Indonesia di Malaysia adalah dengan cara :

a. Penambahan bantuan dana operasional

b. Penambahan peralatan; dan

c. Penambahan karyawan.

\section{DAFTAR PUSTAKA}

Buku:

Lubis, M. Solly.Politik Hukum dan Kebijakan Publik, CV. Mandar Maju, Bandung, 2014.

Marzuki, Peter Mahmud. Penelitian Hukum, Kencana Prenada Media Grup, Jakarta, 2005.

ND. Mukti Fajar dan Achmad,Yulianto.Dualisme Penelitian Hukum, Fakultas Hukum Universitas Muhammadiyah Yogyakarta, Yogyakarta, 2007.

Nasution, S Dan Thomas, M. Buku Penuntun Membuat Tesis, Skripsi, Disertasi, Makalah,Bumi Aksara, Jakarta, 2006.

Ndraha, Taliziduhu.Sumber Daya Manusia, PT. Rajawali, Jakarta, 2002.

Salusu, J. Pengambilan Keputusan Strategik Untuk Organisasi Publik, Grasindo, Jakarta, 1996.

Sastracarito, HS. Kamus Pembina Bahasa Indonesia, Teladan, Surabaya, 2002. Sunggono, Bambang.Metode Penelitian Hukum, Rajawali Pers, Jakarta, 1998.

Wawancara:

Sulaeman T, Fajar selaku Atase Hukum Kedutaan Besar Indonesia di Malaysia

Lekat, Mulkan selaku Atase Imigrasi Kedutaan Besar Indonesia di Malaysia

Internet:

Felix, Rega. woordpress.com/2011/01/15/penerapan-dan-penggunaanpencegahan-dan-penangkalan-keimigrasian-dalam-perspektif-hak-ataskebebasan-bergerak. 